\title{
SAMHD1 expression is associated with low immune activation but not correlated with HIV-1 DNA levels in $\mathrm{CD4}^{+} \mathrm{T}$ cells of patients with $\mathrm{HIV}-1$
}

\author{
JIE LI $^{1 *}$, CHUANHUA GAO ${ }^{2 *}$, SHANSHAN HUANG ${ }^{1}$, LONGTENG JIN ${ }^{3}$ and CHANGZHONG JIN ${ }^{4}$ \\ ${ }^{1}$ Department of Infectious Disease, The Second Affiliated Hospital and Yuying Children's Hospital of Wenzhou \\ Medical University, Wenzhou, Zhejiang 325027; ${ }^{2}$ Laboratory of Biochemistry and Biomaterials, Department \\ of Materials, College of Chemical and Material Engineering, Quzhou University, Quzhou, Zhejiang 324000; \\ ${ }^{3}$ Department of Childhood Infectious Disease, The Second Affiliated Hospital and Yuying Children's Hospital of \\ Wenzhou Medical University, Wenzhou, Zhejiang 325027; ${ }^{4}$ State Key Laboratory for Diagnosis and Treatment \\ of Infectious Diseases, Collaborative Innovation Center for Diagnosis and Treatment of Infectious Diseases, \\ The First Affiliated Hospital, School of Medicine, Zhejiang University, Hangzhou, Zhejiang 310003, P.R. China
}

Received December 1, 2019; Accepted April 7, 2020

DOI: $10.3892 / \mathrm{mmr} .2020 .11153$

\begin{abstract}
Sterile $\alpha$ motif and histidine/aspartic acid domain-containing protein 1 (SAMHD1) can inhibit reverse transcription of human immunodeficiency virus-1 (HIV-1) by hydrolyzing intracellular deoxy-ribonucleoside triphosphate. However, its role in HIV-1 disease progression has not been extensively studied. To study the impacts of SAMHD1 on HIV-1 disease progression, especially on DNA levels, we investigated SAMHD1 levels in the peripheral blood of HIV-1 elite controllers (ECs), antiretroviral therapy (ART) naive viremic progressors (VPs) and patients with HIV-1 receiving ART (HIV-ARTs) compared with healthy controls. In addition, the present study analyzed the relationship between SAMHD1 and interferon- $\alpha$, immune activation and HIV-1 DNA levels. The results of the present study demonstrated elevated SAMHD1 expression in the peripheral blood mononuclear cells of all patients withHIV-1,
\end{abstract}

Correspondence to: Dr Changzhong Jin, State Key Laboratory for Diagnosis and Treatment of Infectious Diseases, Collaborative Innovation Center for Diagnosis and Treatment of Infectious Diseases, The First Affiliated Hospital, School of Medicine, Zhejiang University, 79 Qingchun Avenue, Hangzhou, Zhejiang 310003, P.R. China

E-mail: changzhongjin@163.com

Dr Longteng Jin, Department of Childhood Infectious Disease, The Second Affiliated Hospital and Yuying Children's Hospital of Wenzhou Medical University, 109 Xueyuanxi Street, Wenzhou, Zhejiang 325027, P.R. China

E-mail: jlt786@163.com

*Contributed equally

Key words: sterile $\alpha$ motif and histidine/aspartic acid domain-containing protein 1, HIV-1, elite controllers, HIV-1 DNA, immune activation but higher SAMHD1 expression in the $\mathrm{CD}^{+} \mathrm{T}$ cells of only ECs compared with healthy controls. Immune activation was increased in the VPs and decreased in the ECs compared with healthy controls. Substantially lower HIV-1 DNA levels were identified in ECs compared with those in VPs and HIV-ARTs. SAMHD1 expression was associated with low levels of immune activation. No significant correlation was observed between SAMHD1 and HIV-1 DNA levels. Overall, the findings of the present study indicated that SAMHD1 was highly expressed in ECs, which may be associated with low immune activation levels, but was not directly related to HIV-1 DNA levels.

\section{Introduction}

Host restrictive factors can inhibit human immunodeficiency virus-1 (HIV-1) infection at various stages, and these factors include apolipoprotein B mRNA editing enzyme catalytic subunit $3 \mathrm{G}$ proteins $(1,2)$, Tripartite motif-containing protein $5 \alpha(3,4)$, tetherin/bone marrow stromal cell antigen 2 (5) and sterile $\alpha$ motif and histidine/aspartic acid domain-containing protein 1 (SAMHD1) (6-9). SAMHD1 is a newly discovered HIV-1 host restriction factor, which can be degraded by the viral accessory protein Vpx of HIV-2 and certain simian immunodeficiency viruses (6-10). However, HIV-1 has lost the Vpx protein during evolution (9). Therefore, SAMHD1 is a host restriction factor that cannot be antagonized by HIV-1.

HIV-1 RNA is reversely transcribed into DNA following its fusion to target host cells, and this requires an adequate supply of deoxy-ribonucleoside triphosphate (dNTPs). SAMHD1 is a diguanosine triphosphate-dependent phosphatase that primarily hydrolyzes dNTPs into deoxynucleoside and inorganic triphosphoric acid, thus reducing the nuclear dNTP concentrations and inhibiting the reverse transcription of HIV-1 (11). There are several in vivo studies that have investigated SAMHD1 in the peripheral blood of patients 
with HIV-1 and analyzed its role in disease progression. Riveira-Muñoz et al (12) studied SAMHD1 expression in the $\mathrm{CD}^{+} \mathrm{T}$ cells of patients with HIV-1, including elite controllers (ECs) with sustained plasma viral load below the limit of detection in the absence of antiretroviral treatment and viremic progressors (VPs) with high level of viral load $(>5,000 \mathrm{cp} / \mathrm{ml})$ and notable loss of $\mathrm{CD}^{+}{ }^{+} \mathrm{T}$ cells $(<400 / \mu \mathrm{l})$; the results demonstrated that higher levels of SAMHD1 were present in ECs compared with the healthy controls (HCs) and VPs, suggesting that SAMHD1 may serve a role in controlling viral replication and slowing the rate of disease progression. However, conflicting results were reported in HIV-exposed seronegative (HESN) individuals in other studies $(13,14)$. Therefore, SAMHD1 expression in the peripheral blood of patients with HIV-1, especially in $\mathrm{CD}^{+} \mathrm{T}$ cells, should continue to be investigated. Furthermore, since SAMHD1 restricts the reverse transcription of $\mathrm{HIV}-1$, it may be interesting to study the association between SAMHD1 expression and HIV-1 DNA levels in $\mathrm{CD}^{+}{ }^{+} \mathrm{T}$ cells. The present study aimed to investigate the expression of SAMHD1 CD4 ${ }^{+}$ T cells of patients with HIV-1 receiving antiretroviral therapy (HIV-ARTs), VPs, ECs and HCs, and to study the associations between SAMHD1 expression and immune activation as well as the levels of HIV-1 DNA.

\section{Materials and methods}

Subjects. HIV-1 positive patients with the mean age of 47.75 years (range, 27-62 years) were recruited from the Second Affiliated Hospital and Yuying Children's Hospital of Wenzhou Medical University and the First Affiliated Hospital, School of Medicine, Zhejiang University (Zhejiang, China) between January and September 2018. HIV-1 infection was diagnosed based on the positive results obtained from serological and HIV RNA detection assays. All subjects were volunteers and provided written informed consent to participate in the study. This study was approved by the ethics review boards of The Second Affiliated Hospital and Yuying Children's Hospital of Wenzhou Medical University and the First Affiliated Hospital, School of Medicine, Zhejiang University (Zhejiang, China).

Three groups of patients with HIV-1 were included in the present study: i) 32 VPs who were ART naive and exhibited typical disease progression; ii) 26 HIV-ARTs with suppressed HIV-1 replication, whose viral load was maintained $<50$ copies $/ \mu 1$ or with viral blips $<1,000$ copies $/ \mu 1$; and iii) 15 ECs with a sustained plasma viral load below the limit of detection in the absence of ART (non-consecutive blips of $<2,000$ copies/mlwere allowed if present in $<20 \%$ of viral load determinations) (12). In addition, $28 \mathrm{HCs}$ were recruited from community clinics and comprised individuals who had not suffered from infectious or immune diseases during the previous month. The four groups were age- and sex-matched, and there were no significant differences in the mean $\mathrm{CD}^{+} \mathrm{T}$ cell counts (Table I).

Detection of SAMHDI mRNA in the peripheral blood. Peripheral blood $(\sim 5 \mathrm{ml})$ was collected from the participants into tubes containing EDTA. Peripheral blood mononuclear cells (PBMCs) were isolated by a density gradient centrifugation method (1,000 x $\mathrm{g}$ for 20-30 min at room temperature) using Ficoll-Paque PLUS (GE Healthcare Life Science). CD4 ${ }^{+}$T lymphocytes were purified from the PBMCs using MACS human CD4 microbeads for positive selection (Miltenyi Biotec $\mathrm{GmbH}$ ). The purity of $\mathrm{CD}^{+} \mathrm{T}$ lymphocytes was $>90 \%$. The total RNA was extracted from the PBMCs and $\mathrm{CD}^{+}{ }^{+} \mathrm{T}$ lymphocytes using TRIzol ${ }^{\circledR}$ reagent (Thermo Fisher Scientific, Inc.) and reverse-transcribed into cDNA using a total volume of $20 \mu \mathrm{l}$ with the temperature protocol of $30^{\circ} \mathrm{C}$ for $10 \mathrm{~min}, 42^{\circ} \mathrm{C}$ for $45 \mathrm{~min}$, and $95^{\circ} \mathrm{C}$ for $5 \mathrm{~min}$. The quantitative analysis of SAMHD1 mRNA was performed using reverse transcription-quantitative (RT-q) PCR as previously described (15). Briefly, the reaction mixture included $10 \mu \mathrm{l} \mathrm{SYBR}{ }^{\circledR}$ Green Master Mix (Takara Biotechnology Co., Ltd.), $0.2 \mu \mathrm{l}$ each of the forward and reverse primers, and $2 \mu \mathrm{l}$ cDNA, increased to a final volume of $20 \mu \mathrm{l}$ with RNase-free water. RT-qPCR was performed using a DNA Engine Chromo 4 Real-time qPCR System (Bio-Rad Laboratories, Inc.) and the thermocycling conditions were as follows: 40 cycles of denaturation at $95^{\circ} \mathrm{C}$ for $45 \mathrm{sec}$, annealing at $62^{\circ} \mathrm{C}$ for $30 \mathrm{sec}$ and extension at $72^{\circ} \mathrm{C}$ for $30 \mathrm{sec}$; the dsDNA was measured at $86^{\circ} \mathrm{C}$ after each cycle. GAPDH mRNA was detected as the internal control. The primers used were as follows: SAMHD1 forward, 5'-AAAACCAGGTTTCAC AACTTCTGC-3' and reverse, 5'-TGCGGCATACAAACT CTTTCTGT-3'; and GAPDH forward, 5'-TGCACCACCAAC TGCTTAGC-3' and reverse, 5'-GGCATGGACTGTGGT CATGAG-3'. The relative expression levels of SAMHD1 and GAPDH were calculated using the $2^{-\Delta \Delta \mathrm{Cq}}$ method (16). Each sample was amplified three times.

Detection of plasma interferon (IFN)- $\alpha$ levels. The plasma IFN- $\alpha$ levels were detected using a human IFN- $\alpha$ ELISA kit (cat. no. 41100-1, R\&D Systems, Inc.), according to the manufacturer's instructions. IFN- $\alpha$ concentrations were determined by comparing the samples with a standard curve.

Quantification of HIV-1 RNA and DNA. The HIV-1 viral load in the plasma of patients infected with HIV-1 was quantitatively detected using a standardized RT-qPCR (Cobas Amplicor HIV-1 Monitor Test; version 1.5; Ultra-sensitive specimen preparation; Roche Diagnostic Systems Inc) as previously described (17). The detection limit in the plasma was defined as $50 \mathrm{HIV}-1$ RNA copies/ml.

The total HIV-1 DNA, including the integrated HIV-1 DNA and episomal two long terminal repeat (2LTR) circles, in the peripheral blood was detected using a HIV-1 DNA Detection kit (PCR-Fluorescent Probing; SUPBIO; Guangzhou Hailite Biotechnology Co., Ltd.). Briefly, the total DNA was isolated from the blood using a QIAamp DNA Blood Mini Kit (Qiagen $\mathrm{GmbH})$. The $50 \mu \mathrm{l}$ reaction system contained $5 \mu \mathrm{l}$ DNA and $45 \mu \mathrm{l}$ PCR master mix. The test was performed using a Light Cycler 1.2 (Roche Diagnostics $\mathrm{GmbH}$ ). The amplification conditions were set as follows: i) five cycles of $37^{\circ} \mathrm{C}$ for $5 \mathrm{~min}$, $95^{\circ} \mathrm{C}$ for $10 \mathrm{~min}$; ii) $95^{\circ} \mathrm{C}$ for $15 \mathrm{sec}, 65^{\circ} \mathrm{C}$ for $15 \mathrm{sec}$ and $72^{\circ} \mathrm{C}$ for $20 \mathrm{sec}$; iii) 40 cycles of $95^{\circ} \mathrm{C}$ for $15 \mathrm{sec}, 62^{\circ} \mathrm{C}$ for $15 \mathrm{sec}$ and $72^{\circ} \mathrm{C}$ for $20 \mathrm{sec}$; and iv) 10 cycles of $95^{\circ} \mathrm{C}$ for $15 \mathrm{sec}, 52^{\circ} \mathrm{C}$ for $15 \mathrm{sec}$ and $72^{\circ} \mathrm{C}$ for $32 \mathrm{sec}$. Two standard curves were calculated according to the volume of blood or PBMC counts. The results were expressed as copies $/ \mathrm{ml}$ and copies $/ 10^{6} \mathrm{PBMCs}$. 
Table I. Clinical information of the subjects.

\begin{tabular}{|c|c|c|c|c|c|}
\hline Variable & $\mathrm{HCs}$ & VPs & HIV-ARTs & ECs & P-value \\
\hline Number & 28 & 32 & 26 & 15 & \\
\hline Male (\%) & $17(60.71 \%)$ & $19(59.38 \%)$ & $17(65.38 \%)$ & $4(80.00 \%)$ & 0.37 \\
\hline Age, years & $31.35 \pm 14.63$ & $38.71 \pm 7.63$ & $42.66 \pm 11.57$ & $36.81 \pm 15.19$ & 0.53 \\
\hline Viral load $\left(\log _{10}\right)$ & - & $4.35 \pm 1.42$ & $1.74 \pm 1.01$ & - & $<0.01^{\mathrm{a}}$ \\
\hline $\mathrm{CD}^{+}{ }^{+} \mathrm{T}$ cells $/ \mu \mathrm{l}$ & $702.66 \pm 142.82$ & $356.17 \pm 188.83$ & $517.05 \pm 161.20$ & $637.58 \pm 216.33$ & $0.01^{\mathrm{a}}$ \\
\hline $\mathrm{CD}^{+}{ }^{+} \mathrm{T}$ cells $/ \mu \mathrm{l}$ & $674.46 \pm 228.94$ & $1,056.81 \pm 523.02$ & $835.88 \pm 370.36$ & $747.88 \pm 298.36$ & 0.17 \\
\hline
\end{tabular}

${ }^{\mathrm{a}} \mathrm{P}<0.05$. HIV, human immunodeficiency virus; HCs, healthy controls; VPs, viremic progressors; HIV-ARTs, patients with HIV-1 receiving antiretroviral therapy; ECs, elite controllers.

Flow cytometry. $\mathrm{CD} 4^{+}, \mathrm{CD}^{+}$and activated $\mathrm{CD} 4^{+} \mathrm{CD} 38^{+}$ human leukocyte antigen (HLA)-DR ${ }^{+} \mathrm{T}$ cells in the peripheral blood were measured by flow cytometry (FACSCantoII; Becton, Dickinson and Company) using BD FACSCanto II System Software Upgrade (v 3.0); Becton, Dickinson and Company. The cell counts for $\mathrm{CD}^{+} \mathrm{CD} 4^{+}$, $\mathrm{CD}^{+}{ }^{+} \mathrm{CD}^{+}{ }^{+}$and activated $\mathrm{CD} 3{ }^{+} \mathrm{CD} 4{ }^{+} \mathrm{CD} 38^{+} \mathrm{HLA}-\mathrm{DR}^{+}$ $\mathrm{T}$ cells were determined by a five-color strategy using anti-CD3-allophycocyanin, anti-CD4-fluorescein isothiocyanate, anti-CD8-phycoerythrin-Cy7, anti-CD38-phycoerythrin, and anti-HLA-DR-Peridinin Chlorophyll Protein Complex-Cy5.5 (Becton, Dickinson and Company). Cell staining was performed according to the manufacturer's instructions.

Statistical analysis. Data are presented as the mean \pm standard deviation. The statistical analyses were performed using SPSS 20.0 (IBM Corp.). One-way analysis of variance with Bonferroni's post hoc test was used when comparing three or more groups. Correlations were tested using the Pearson correlation analysis. All tests were two-tailed. $\mathrm{P}<0.05$ was considered to indicate a statistically significant difference

\section{Results}

Levels of SAMHDI increase in the PBMCs of VPs and $H I V$-ARTs. SAMHD1 expression was detected in the PBMCs and $\mathrm{CD}^{+} \mathrm{T}$ cells of patients with HIV-1 and HCs. SAMHD1 mRNA expression was significantly increased in the PBMCs of VPs, HIV-ARTs and ECs compared with that in the HCs, with the highest level exhibited by the EC group; however, no significant differences were observed in the SAMHD1 levels in the PBMCs between the three groups of patients with HIV-1 (Fig. 1A). In addition, the SAMHD1 levels in the $\mathrm{CD}^{+} \mathrm{T}$ cells were significantly elevated in the ECs compared with those of the VPs, the HIV-ARTs and the HCs, but no significant differences were observed in CD4 ${ }^{+} \mathrm{T}$-cell expression of SAMHD1 between the VPs, the HIV-ARTs and the HCs (Fig. 1B). The relationship between SAMHD1 levels in $\mathrm{CD}^{+} \mathrm{T}$ cells, the $\mathrm{CD}^{+} \mathrm{T}$ cell count and the viral load were also analyzed. No significant correlations were observed between the expression of SAMHD1 in $\mathrm{CD}^{+} \mathrm{T}$ cells, the $\mathrm{CD} 4^{+} \mathrm{T}$-cell count or the viral load (Table II).
Table II. Correlation between SAMHD1 expression levels in $\mathrm{CD}^{+} \mathrm{T}$ cells and immunological and virological indexes.

\begin{tabular}{lcc}
\hline SAMHD1 mRNA in CD4 ${ }^{+}$T cells vs. & $\mathrm{R}$ & P-value \\
\hline $\mathrm{CD}^{+}$T cells, $\left./ \mu \mathrm{l}\right)$ & 0.064 & 0.683 \\
Viral load, cp/ml) & -0.306 & 0.107 \\
IFN- $\alpha, \mathrm{pg} / \mathrm{ml})$ & -0.218 & 0.164 \\
$\mathrm{CD}^{+} \mathrm{CD} 38^{+} \mathrm{HLA}-\mathrm{DR}^{+}$T cells, $\%$ & -0.401 & $0.013^{\mathrm{a}}$ \\
HIV-1 DNA/10 ${ }^{6}$ PBMC & -0.168 & 0.596 \\
HIV-1 DNA/ml blood & 0.032 & 0.357
\end{tabular}

${ }^{\mathrm{a}} \mathrm{P}<0.05$. SAMHD1, sterile $\alpha$ motif and histidine/aspartic acid domain-containing protein 1 ; HIV, human immunodeficiency virus; IFN, interferon; PBMCs, Peripheral blood mononuclear cells; HLA-DR, human leukocyte antigen-DR.

SAMHD1 expression is associated with the low level of $C D 4^{+}$T-cell activation. The secretion of IFN- $\alpha$ and the level of $\mathrm{T}$ cell activation are typically increased during a viral infection (18-20). Considering that SAMHD1 expression is affected by IFNs and immune activation (21), the concentration of IFN- $\alpha$ in the plasma and the percentage of activated $\mathrm{CD}^{+} \mathrm{T}$ cells in patients withHIV-1 and HCs were assessed. No significant differences were observed in the plasma IFN- $\alpha$ levels between patients with HIV-1 and the HCs (Fig. 2A). Flow cytometric analysis revealed significantly higher immune activation of $\mathrm{CD}^{+}$T cells in the VPs and the HIV-ARTs (Fig. 2B) compared with those in the ECs and the HCs. In addition, the activation of $\mathrm{CD}^{+}{ }^{+} \mathrm{T}$ cells in ECs was lower compared with that in HCs, VPs and HIV-ARTs (Fig. 2B). Correlation analysis revealed that SAMHD1 expression was inversely correlated with the activation of $\mathrm{CD}^{+} \mathrm{T}$ cells; no correlation was observed between SAMHD1 expression in $\mathrm{CD} 4^{+} \mathrm{T}$ cells and plasma IFN- $\alpha$ levels (Table II).

Total HIV-1 DNA levels in ECs are not correlated with the levels of SAMHD1 expression. Whether the total HIV-1 DNA levels in the peripheral blood correlated with SAMHD1 expression in $\mathrm{CD}^{+} \mathrm{T}$ cells was further determined. The total HIV-1 DNA levels in the VPs were $612.86 \pm 248.95$ copies $/ 10^{6}$ PBMCs or $708.52 \pm 427.30$ copies/ml blood, which was 
A

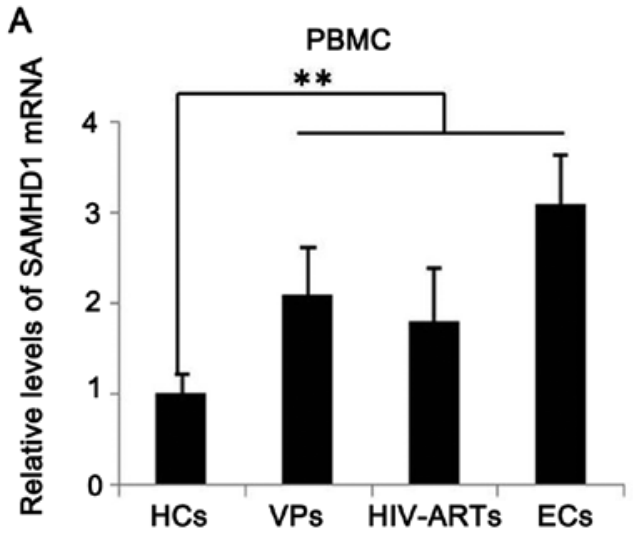

B

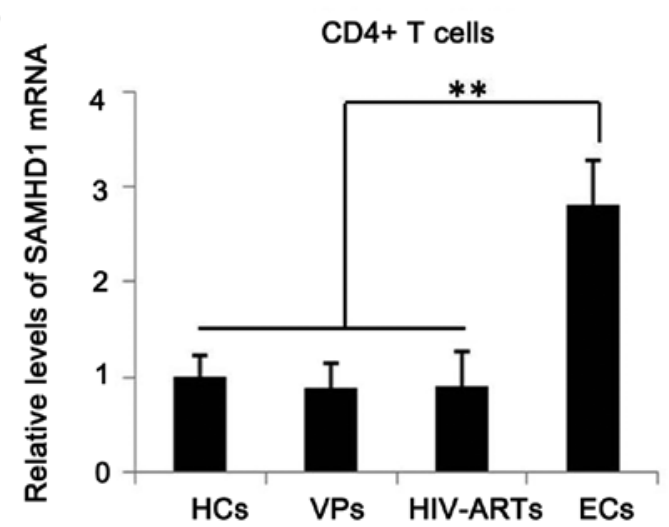

Figure 1. SAMHD1 expression in patients with HIV-1. Relative levels of SAMHD1 mRNA in the (A) PBMCs and (B) CD4+ T cells of patients with HIV-1 and healthy controls were detected by qRT-PCR. The level of SAMHD1 expression in the healthy controls was set to 1 . ${ }^{* *} \mathrm{P}<0.01$. SAMHD1, sterile $\alpha$ motif and histidine/aspartic acid domain-containing protein 1; PBMCs, Peripheral blood mononuclear cells; HIV, human immunodeficiency virus; HCs, healthy controls; VPs, viremic progressors; HIV-ARTs, patientswith HIV-1 receiving antiretroviral therapy; ECs, elite controllers.

A

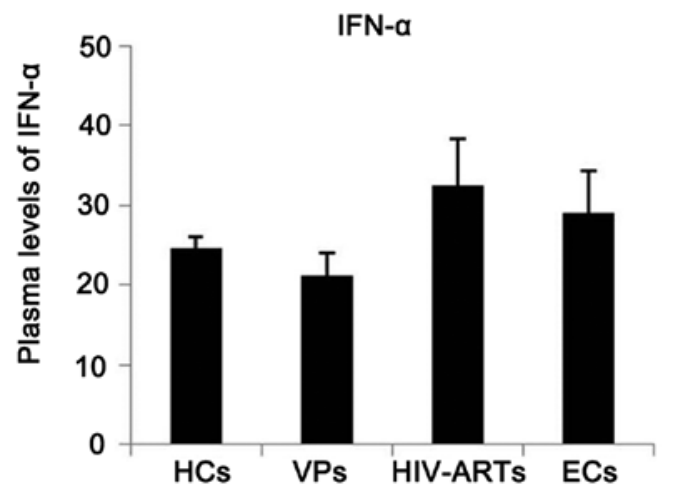

B

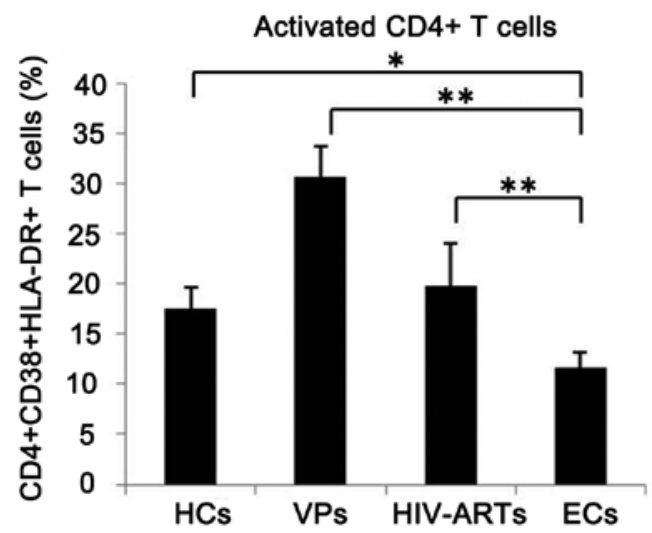

Figure 2. Levels of immune activation markers in patients with HIV-1. (A) Interferon- $\alpha$ in the plasma and (B) percentage of activated CD4+ ${ }^{+}$cells in patients with HIV-1 and healthy controls were detected. ${ }^{*} \mathrm{P}<0.05,{ }^{* *} \mathrm{P}<0.01$. HIV, human immunodeficiency virus; HCs, healthy controls; VPs, viremic progressors; HIV-ARTs, patientswith HIV-1 receiving antiretroviral therapy; ECs, elite controllers.

A

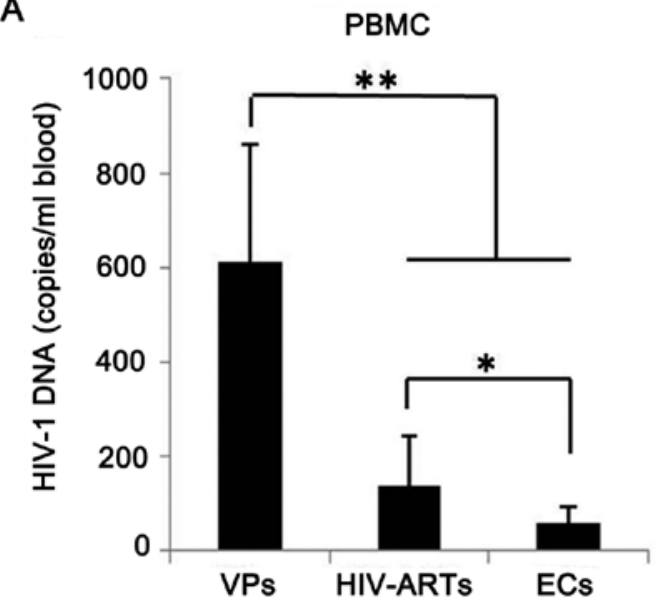

B

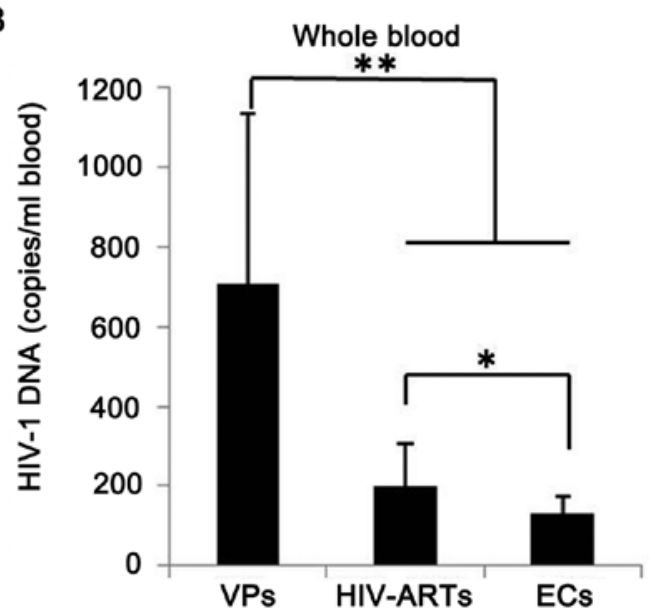

Figure 3. Levels of total HIV-1 DNA in the peripheral blood of patients with HIV-1. The total HIV-1 DNA levels were determined as (A) copies/10 ${ }^{6}$ PBMCs and (B) copies/ml blood. "P<0.05, ${ }^{* *} \mathrm{P}<0.01$. HIV, human immunodeficiency virus; PBMCs, Peripheral blood mononuclear cells; VPs, viremic progressors; HIV-ARTs, patients with HIV-1 receiving antiretroviral therapy; ECs, elite controllers.

significantly higher compared with those in the HIV-ARTs (137.30 \pm 105.04 copies $/ 10^{6} \mathrm{PBMC}$ or $201.76 \pm 103.04 \mathrm{copies} / \mathrm{ml}$ blood) and in the ECs $\left(61.26 \pm 30.69\right.$ copies $/ 10^{6} \mathrm{PBMC}$ and
131.26 \pm 42.66 copies $/ \mathrm{ml}$ blood) (Fig. 3). The total HIV-1 DNA levels exhibited by the ECs were also lower compared those in the HIV-ARTs. The total HIV-1 DNA levels did 
not correlate with SAMHD1 expression in $\mathrm{CD}^{+} \mathrm{T}$ cells (Table II).

\section{Discussion}

In addition to myeloid cells, SAMHD1 is also important for HIV-1 infection of CD4 ${ }^{+} \mathrm{T}$ lymphocytes (22-24). Over expression of SAMHD1 in $\mathrm{CD}^{+} \mathrm{T}$ cell lines alters the permissibility of HIV-1 infection (22), and higher SAMHD1 expression has been observed in resting $\mathrm{CD} 4^{+} \mathrm{T}$ cells that are resistant to HIV-1 infection compared with those in activated CD4 ${ }^{+}$ $\mathrm{T}$ cells $(23,24)$. In addition, Riveira-Muñoz et al (12) demonstrated elevated SAMHDlexpression in the $\mathrm{CD} 4^{+} \mathrm{T}$ cells of HIV-1-positive ECs compared with the HCs and VPs, indicating an important role for SAMHD1 in HIV-1 resistance. However, inconsistent results have been reported by other researchers; for example, Gonzalez et al (13) demonstrated that SAMHD1 expression was higher in the oral and genital mucosa and lower in the PBMCs of HESN individuals who were resistant to HIV-1compared with HCs. In addition, Santos et al (14) reported that no significant differences were observed in the basal SAMHD1 mRNA expression levels in the $\mathrm{CD}^{+} \mathrm{T}$ cells of HESN individuals compared with those of HCs and HIV-ARTs. The results of the present study revealed higher SAMHD1 expression in the $\mathrm{CD}^{+} \mathrm{T}$ cells of ECs compared with those of HCs, which was consistent with the findings of the study by Riveira-Muñoz et al (12). In addition, there were no differences in the SAMHD1 levels of CD4 ${ }^{+}$ T cells between the HIV-ARTs, VPs and HCs. Notably, the present study demonstrated higher SAMHD1 expression in the PBMCs of the HIV-ARTs and the VPs compared with the HCs, but no significant deference was observed in the $\mathrm{CD} 4^{+} \mathrm{T}$ cells. One reason for these findings may be related to the altered PBMC components present in patients with HIV-1. PBMCs consist of a mixture of different cell types, including myeloid cells with elevated SAMHD1 expression and lymphoid cells with low levels of SAMHD1 $(22,25)$. As a result of the loss of $\mathrm{CD}^{+} \mathrm{T}$ cells, HIV-1 VPs exhibit a higher percentage of myeloid cells and correspondingly higher SAMHD1 levels in their PBMCs. Other reasons for the higher SAMHD1 levels in the PBMCs of patients with HIV-1 need to be explored in future studies. The use of different subjects (e.g., ECs, HESN individuals, and patients receiving ART or not) and the types of cells investigated (e.g., $\mathrm{PBMCs}$ or $\mathrm{CD} 4^{+} \mathrm{T}$ cells) may explain the inconsistent results among published studies.

The expression of SAMHD1 can be induced by IFNs $(15,26)$; however, it is unclear whether the in vivo expression of SAMHD1 is affected by plasma IFN levels. The present study assessed plasma IFN- $\alpha$ levels and the effects on SAMHD1 expression in $\mathrm{CD}^{+} \mathrm{T}$ cells. No differences in the plasma IFN- $\alpha$ levels were observed in any of the four subject groups. In addition, there was no correlation between IFN- $\alpha$ and SAMHD1 expression levels. Another potential factor impacting SAMHD1 expression in $\mathrm{CD}^{+} \mathrm{T}$ cells is immune activation (21). SAMHD1 is highly expressed in resting $\mathrm{CD} 4^{+}$ $\mathrm{T}$ cells but is decreased during CD $4^{+} \mathrm{T}$ cell activation and proliferation $(21,23,24)$. Consistent with previous studies $(27,28)$ indicating that HIV-1 patients have increased $\mathrm{CD}^{+} \mathrm{T}$ activation, the present study demonstrated that the percentage of activated $\mathrm{CD}^{+} \mathrm{T}$ cells was increased in the HIV-ARTs and the
VPs, but was decreased in the ECs compared with the HCs. In addition, SAMHD1 expression was inversely correlated with $\mathrm{CD}^{+}{ }^{+} \mathrm{T}$-cell activation. SAMHD1 is reported to be an important negative regulator of the IFN response and immune activation (29), which may explain the reverse relationship between SAMHD1 and immune activation. Another explanation may be that immune activation induced by HIV-1 infection can increase the proportion of activated $\mathrm{CD} 4^{+} \mathrm{T}$ cells with low SAMHD1 expression and decrease the proportion of resting $\mathrm{CD} 4^{+} \mathrm{T}$ cells with high SAMHD1 expression (27). The results of the present study suggested that high SAMHD1 expression correlates with a low percentage of activated $\mathrm{CD}^{+} \mathrm{T}$ cells, and therefore, HIV-1 target cells. Thus, the elevated expression of SAMHD1 in the CD4 ${ }^{+} \mathrm{T}$ cells of ECs may restrict HIV-1 infection by inhibiting viral reverse transcription as well as the extent of immune activation.

The inhibition of reverse transcription by SAMHD1 results in the reduced production of total HIV-1 DNA (30), which contains two components: Integrated HIV-1 DNA and episomal 2LTR circles, which are transient by-products of failed HIV-1 DNA integration (31). The total level of HIV-1 DNA has been demonstrated to be inversely correlated with the time to viral rebound in patients treated early with interrupted ART (32). The results of the present study demonstrated lower total HIV-1 DNA levels in the peripheral blood of the ECs compared with the VPs and the HIV-ARTs; however, no correlation was observed between SAMHD1 expression and the total HIV-1 DNA levels. The function of SAMHD1 is affected by post-transcriptional and post-translational modifications (33). Phosphorylation of SAMHD1 T592 can abolish the dNTPase activity of SAMHD1 (33). In addition to SAMHD1, the total HIV-1 DNA levels can be impacted by a variety of other factors. For example, high HIV-1 RNA production leads to high total HIV-1 DNA levels, and the number and percentage of activated $\mathrm{CD} 4^{+} \mathrm{T}$ cells can also impact the total level of HIV-1 DNA $(34,35)$. Additionally, the total HIV-1 DNA level can be affected by the formation of episomal 2LTR circles (36). Cytosolic DNA (e.g. double-stranded HIV-1 DNA, including episomal 2LTR circles) is sensed by the cyclic GMP-AMP synthase/stimulator of interferon genes cytosolic DNA-sensing pathway in HIV-1 infected cells, resulting in a spontaneous IFN response and subsequent immune activation (37). Therefore, reduced production of HIV-1 DNA by SAMHD1 may limit the magnitude of IFN and effector T cell responses.

The limitations associated with the present study were as follows: i) The levels of integrated HIV-1 DNA and episomal 2LTR circles were not investigated separately due to technological limitations; ii) the number of ECs was small; and iii) the mRNA rather than protein levels of SAMHD1 in purified $\mathrm{CD} 4^{+} \mathrm{T}$ cells from patients with HIV-1 were only investigated due to limited volume of blood samples. Future studies with an expanded sample size should be carried out to further explore the expression of SAMHD1 in patients withHIV-1 exhibiting differential disease progression as well as the relationship between SAMHD1 and HIV-1 DNA.

In summary, the results of the present study indicated that SAMHD1 was highly expressed in ECs and may contribute to low total HIV-1 DNA levels and low immune activation observed in individuals infected with HIV-1 compared with 
those in HCs. However, no correlation was observed between SAMHD1 expression and the HIV-1 DNA levels. The results of the present study also suggested that SAMHD1 may restrict HIV-1 infection in vivo by inhibiting immune activation and thus reducing the number of HIV-1 target cells instead of directly inhibiting HIV-1 reverse transcription. This study also emphasized the importance of reducing the immune activation levels of $\mathrm{CD}^{+} \mathrm{T}$ cells for patients with HIV-1. To the best of our knowledge, this is the first in vivo study on the relationship between SAMHD1 and HIV-1 DNA levels in $\mathrm{CD}^{+}{ }^{+} \mathrm{T}$ cells.

\section{Acknowledgements}

Not applicable.

\section{Funding}

The present study was supported by the Zhejiang Provincial Natural Science Foundation (grant no. QY20H190002).

\section{Availability of data and materials}

The datasets used and/or analyzed during the current study are available from the corresponding author on reasonable request.

\section{Authors' contributions}

JL, CG and CJ contributed to study concept and design. SH and $\mathrm{LJ}$ contributed to the clinical sampling. JL, CG, SH and CJ performed the experiments, and acquired, analyzed or interpreted data. JL, CG and CJ drafted and revised the manuscript. All authors read and approved the final manuscript.

\section{Ethics approval and consent to participate}

This study was approved by the ethics review boards of The Second Affiliated Hospital and Yuying Children's Hospital of Wenzhou Medical University (No. 201700837) and the First Affiliated Hospital, School of Medicine, Zhejiang University (approval no. IIT20171207A). Written informed consent to participate was obtained from all subjects.

\section{Patient consent for publication}

Not applicable.

\section{Competing interests}

The authors declare that they have no competing interests.

\section{References}

1. Reddy K, Ooms M, Letko M, Garrett N, Simon V and Ndung'u T: Functional characterization of Vif proteins from HIV-1 infected patients with different APOBEC 3G haplotypes. AIDS 30: 1723-1729, 2016.

2. Bertine M, Charpentier C, Visseaux B, Storto A, Collin G, Larrouy L, Damond F, Matheron S, Brun-Vézinet F and Descamps D; ANRS CO5 HIV-2 Cohort: High level of APOBEC3F/3G editing in HIV-2 DNA vif and pol sequences from antiretroviral-naive patients. AIDS 29: 779-784, 2015.

3. Merindol N and Berthoux L: Restriction factors in HIV-1 disease progression. Curr HIV Res 13: 448-461, 2015.
4. Nakayama EE and Shioda T: Impact of TRIM5alpha in vivo. AIDS 29: 1733-1743, 2015.

5. Li SX, Barrett BS, Guo K and Santiago ML: Tetherin/BST-2. Restriction factor or immunomodulator? Curr HIV Res 14: 235-246, 2016.

6. Lahouassa H, Daddacha W, Hofmann H, Ayinde D, Logue EC, Dragin L, Bloch N, Maudet C, Bertrand M, Gramberg T, et al: SAMHD1 restricts the replication of human immunodeficiency virus type 1 by depleting the intracellular pool of deoxynucleoside triphosphates. Nat Immunol 13: 223-228, 2012.

7. St Gelais C and Wu L: SAMHD1: A new insight into HIV-1 restriction in myeloid cells. Retrovirology 8: 55, 2011.

8. Jermy A: Viral infection: SAMHD1 cuts the power to HIV-1. Nat Rev Microbiol 10: 237, 2012.

9. Laguette $\mathrm{N}$ and Benkirane M: How SAMHD1 changes our view of viral restriction. Trends Immunol 33: 26-33, 2012.

10. Kang J, Hou J, Zhao K, Yu XF and Du J: HD domain of SAMHD1 influences Vpx-induced degradation at a post-interaction step. Biochem Biophys Res Commun 470: 690-696, 2016.

11. Powell RD, Holland PJ, Hollis $\mathrm{T}$ and Perrino FW: Aicardi-Goutieres syndrome gene and HIV-1 restriction factor SAMHD1 is a dGTP-regulated deoxynucleotide triphosphohydrolase. J Biol Chem 286: 43596-43600, 2011.

12. Riveira-Muñoz E, Ruiz A, Pauls E, Permanyer M, Badia R, Mothe B, Crespo M, Clotet B, Brander C, Ballana E and Esté JA: Increased expression of SAMHD1 in a subset of HIV-1 elite controllers. J Antimicrob Chemother 69: 3057-3060, 2014.

13. Gonzalez SM, Taborda NA, Feria MG, Arcia D, Aguilar-Jiménez W, Zapata W and Rugeles MT: High expression of antiviral proteins in mucosa from individuals exhibiting resistance to human immunodeficiency virus. PLoS One 10: $\mathrm{e} 0131139,2015$.

14. Santos ÍM, da Rosa EA, Gräf T, Ferreira LG, Petry A, Cavalheiro F, Reiche EM, Zanetti CR and Pinto AR: Analysis of immunological, viral, genetic, and environmental factors that might be associated with decreased susceptibility to HIV infection in serodiscordant couples in florianopolis, Southern Brazil. AIDS Res Hum Retroviruses 31: 1116-1125, 2015.

15. Jin C, Peng X, Liu F, Cheng L, Lu X, Yao H, Wu H and Wu N: MicroRNA-181 expression regulates specific post-transcriptional level of SAMHD1 expression in vitro. Biochem Biophys Res Commun 452: 760-767, 2014.

16. Livak KJ and Schmittgen TD: Analysis of relative gene expression data using real-time quantitative PCR and the 2(-Delta Delta C(T)) method. Methods 25: 402-408, 2001.

17. Khopkar P, Mallav V, Chidrawar S and Kulkarni S: Comparative evaluation of the Abbott HIV-1 RealTime ${ }^{\mathrm{TM}}$ assay with the standard Roche COBAS ${ }^{\circledR}$ Amplicor ${ }^{\mathrm{TM}}$ HIV-1 Monitor ${ }^{\circledR}$ Test, v1.5 for determining HIV-1 RNA levels in plasma specimens from Pune, India. J Virol Methods 191: 82-87, 2013.

18. Shmagel KV, Saidakova EV, Shmagel NG, Korolevskaya LB, Chereshnev VA, Robinson J, Grivel JC, Douek DC, Margolis L, Anthony DD and Lederman MM: Systemic inflammation and liver damage in HIV/hepatitis C virus coinfection. HIV Med 17: 581-589, 2016.

19. Nguyen TP, Shukla S, Asaad R, Freeman ML, Lederman MM, Harding CV and Sieg S: Responsiveness to IL-7 but not to IFN-alpha is diminished in CD4+ T cells from treated HIV infected patients who experience poor CD4+ T-cell recovery. AIDS 30: 2033-2042, 2016.

20. Jin C, Ji S, Xie T, Höxtermann S, Fuchs W, Lu X, Wu H, Cheng L, Skaletz-Rorowski A, Brockmeyer NH and Wu N: Severe dyslipidemia and immune activation in HIV patients with dysglycemia. HIV Clin Trials 17: 189-196, 2016.

21. Ruffin N, Brezar V, Ayinde D, Lefebvre C, Schulze Zur, Wiesch J, van Lunzen J, Bockhorn M, Schwartz O, Hocini H, et al: Low SAMHD1 expression following T-cell activation and proliferation renders CD4+ T cells susceptible to HIV-1. AIDS 29: 519-530, 2015.

22. Hrecka K, Hao C, Gierszewska M, Swanson SK, Kesik-Brodacka M, Srivastava S, Florens L, Washburn MP and Skowronski J: Vpx relieves inhibition of HIV-1 infection of macrophages mediated by the SAMHD1 protein. Nature 474: 658-661, 2011.

23. Baldauf HM, Pan X, Erikson E, Schmidt S, Daddacha W, Burggraf $M$, Schenkova K, Ambiel I, Wabnitz G, Gramberg T, et al: SAMHD1 restricts HIV-1 infection in resting CD4(+) T cells. Nat Med 18: 1682-1687, 2012.

24. Wu L: SAMHD1: A new contributor to HIV-1 restriction in resting CD4+ T-cells. Retrovirology 9: 88, 2012. 
25. Laguette N,Sobhian B,Casartelli N,Ringeard M,Chable-BessiaC, Ségéral E, Yatim A, Emiliani S, Schwartz $\mathrm{O}$ and Benkirane $\mathrm{M}$ SAMHD1 is the dendritic- and myeloid-cell-specific HIV-1 restriction factor counteracted by Vpx. Nature 474: 654-657, 2011.

26. Jin C, Peng X, Liu F, Cheng L, Xie T, Lu X, Wu H and Wu N: Interferon-induced sterile alpha motif and histidine/aspartic acid domain-containing protein 1 expression in astrocytes and microglia is mediated by microRNA-181a. AIDS 30: 2053-2064 2016.

27. Jin C, Zhang F, Wu L, Xie T, Cheng Y, Tang Z and Wu N: Immune activation and CD127 expression on T lymphocyte subsets of a Chinese cohort of pediatric AIDS patients with different viral responses. Curr HIV Res 10: 584-591, 2012.

28. Jin C, Cheng L, Hoxtermann S, Höxtermann S, Xie T, Lu X, $\mathrm{Wu} \mathrm{H}$, Skaletz-Rorowski A, Brockmeyer $\mathrm{NH}$ and $\mathrm{Wu} \mathrm{N}$ : MicroRNA-155 is a biomarker of T-cell activation and immune dysfunction in HIV-1-infected patients. HIV Med 18: 354-362, 2017.

29. Rice GI, Bond J, Asipu A, Brunette RL, Manfield IW, Carr IM, Fuller JC, Jackson RM, Lamb T, Briggs TA, et al: Mutations involved in Aicardi-Goutières syndrome implicate SAMHD1 as regulator of the innate immune response. Nat Genet 41: 829-832, 2009.

30. Kim B, Nguyen LA, Daddacha W and Hollenbaugh JA: Tight interplay among SAMHD1 protein level, cellular dNTP levels, and HIV-1 proviral DNA synthesis kinetics in human primary monocyte-derived macrophages. J Biol Chem 287: 21570-21574, 2012.

31. Kiselinova M, De Spiegelaere W, Buzon MJ, Malatinkova E, Lichterfeld $M$ and Vandekerckhove L: Integrated and total HIV-1 DNA predict ex vivo viral outgrowth. PLoS Pathog 12: e1005472, 2016
32. Williams JP, Hurst J, Stöhr W, Robinson N, Brown H, Fisher M, Kinloch S, Cooper D, Schechter M, Tambussi G, et al: HIV-1 DNA predicts disease progression and post-treatment virological control. Elife 3: e03821, 2014.

33. Welbourn S, Dutta SM, Semmes OJ and Strebel K: Restriction of virus infection but not catalytic dNTPase activity is regulated by phosphorylation of SAMHD1. J Virol 87: 11516-11524, 2013.

34. Weiss L, Chevalier MF, Assoumou L, Didier C, Girard PM, Piketty C, Costagliola D and Rouzioux C; ANRS 116 SALTO Study Group: T-cell activation positively correlates with cell-associated HIV-DNA level in viremic patients with primary or chronic HIV-1 infection. AIDS 28: 1683-1687, 2014.

35. Geretti AM, Arribas JR, Lathouwers E, Foster GM, Yakoob R, Kinloch S, Hill A, van Delft Y and Moecklinghoff C: Dynamics of cellular HIV-1 DNA levels over 144 weeks of darunavir/ritonavir monotherapy versus triple therapy in the MONET trial. HIV Clin Trials 14: 45-50, 2013.

36. Cuzin L, Pugliese P, Sauné K, Allavena C, Ghosn J, Cottalorda J, Rodallec A, Chaix ML, Fafi-Kremer S, Soulié C, et al: Levels of intracellular HIV-DNA in patients with suppressive antiretroviral therapy. AIDS 29: 1665-1671, 2015.

37. Maelfait J,Bridgeman A, Benlahrech A, Cursi C and Rehwinkel J: Restriction by SAMHD1 limits cGAS/STING-dependent innate and adaptive immune responses to HIV-1. Cell Rep 16: 1492-1501, 2016

(i)(9) This work is licensed under a Creative Commons c) Attribution-NonCommercial-NoDerivatives 4.0 International (CC BY-NC-ND 4.0) License. 